\title{
Traumatic Uterine Rupture Following a Traffic Accident: About a Case
}

\author{
Touré Ecra Ana*, AKA Kacou Edele, Konan Perel, Koffi Koffi Abdoul, Olou Luc \\ University Félix Houphoüet Boigny, Abidjan, Côte d'Ivoire \\ Email: *anaecra@yahoo.fr
}

How to cite this paper: Ana, T.E., Edele, A.K., Perel, K., Abdoul, K.K. and Luc, O. (2017) Traumatic Uterine Rupture Following a Traffic Accident: About a Case. Open Journal of Obstetrics and Gynecology, 7, 957-965.

https://doi.org/10.4236/ojog.2017.79097

Received: July 15, 2017

Accepted: September 18, 2017

Published: September 21, 2017

Copyright $\odot 2017$ by authors and Scientific Research Publishing Inc. This work is licensed under the Creative Commons Attribution International License (CC BY 4.0).

http://creativecommons.org/licenses/by/4.0/ Maternal mortality remains high in developing countries despite the various (c) (i) Open Access

\section{Keywords}

Trauma, Road Accident, Uterine Rupture, Côte d'Ivoire, Africa

\section{Introduction}

\begin{abstract}
The authors report the case of a pregnant victim of a road accident, complicated by uterine rupture. The maternal outcome was favorable, with a fetal death. The interest of this observation lies in the 3 delays described by Thaddeus and Maine involved in the maternal mortality of the developing countries.
\end{abstract}

health programs implemented by governments. The delays in the management take a large place in the causes of this mortality as Thaddéus and Maine so well demonstrated in their model. This observation makes it possible to highlight the precariousness of care and certain factors favoring this precariousness, and it also shows how the age and poverty of technical platforms negatively impacts health care. The age of the technical platforms and the implication of the delay in management remain palpable in the high rate of maternal mortality.

\section{Medical Observation}

Mrs. A.A MF, GIP0, 31 years old, cleaning operative, was evacuated from a peripheral private health center to the gynecological emergency department of the Yopougon teaching hospital (Abidjan, Côte d'Ivoire) for a clinical picture of haemoperitoneum.

The patient was victim of a traffic accident that occurred 6 hours before.

The interrogation made it possible to find the circumstances of this accident: 
the patient would have been frightened by a sound warning, and in a movement of flight, would have made a fall with impact on the abdomen.

Given the intensity of the abdominal pain, the patient was immediately transported by the driver of the offending vehicle to the nearest health center and dropped her off at 200 meters from the center. Thereby, the patient reached the health center on foot.

The patient will be examined by the gynecologist, who will conclude with a haemoperitoneum, and ask her medical evacuation to the teaching hospital of Yopougon for "insufficiency of the technology platform".

The patient knew she was four or five-month pregnant, but she had not yet performed an ultrasound. Pregnancy was confirmed just by a urine pregnancy test.

The patient's medical and surgical history was indistinctive.

At the initial medical examination (six hours later) state of consciousness was normal, conjunctiva were pale, blood pressure was at 104/71 $\mathrm{mm} \mathrm{Hg}$, the pulse was at 112 beats per minute. There were no signs of respiratory distress.

There was an abdominal muscle guarding with umbilicus cry. Examination with the vagina speculum showed a slight haemorrhage coming out of uterus, made of sepia blood, the cervix was healthy;

The vaginal examination revealed a long, posterior, softened, closed, cervix the evaluation of the uterine contours was certainly made difficult by the pain, but the soft and cautious research did not make it possible either $r$ to find a fundus uterine which should have normally been clearly perceived in the vicinity of the umbilicus according to the theoretical gestational age.

The rest of medical examination was normal.

The diagnosis of haemoperitoneum was immediately evoked secondary to a very likely uterine rupture. The indication of laparotomy was thereby posed in emergency.

A bottle of macromolecule started, before the blood was made available, and a preoperative assessment was requested which shows a $\mathrm{B}+$ blood group, a hemoglobin level of $3.5 \mathrm{~g} / \mathrm{dl}$ and platelets to $120,000 / \mathrm{mm}^{3}$; (the minimum reference values being respectively $11 \mathrm{~g} / \mathrm{dl}$ and $150,000 \mathrm{~mm}^{3}$ ).

A laparotomy was performed.

From the opening of the peritoneum, we found:

-A dead, fresh, male fetus weighing $300 \mathrm{~g}$ in its intact pocket with its appendages (Figure 1).

-A $2000 \mathrm{ml}$ haemoperitoneum.

The aspiration of this incoagulable blood made it possible to make the balance of the lesions: a complete and complex uterine rupture composed of 2 uterine damages:

-A left bodily lateral damage extending outward the fundus uteri, measuring 4 centimeters (Figure 2, Figure 3).

-An anterior and above-isthmian damage measuring about 1.5 centimeters (Figure 4).

-Tubes and ovaries were healthy. 


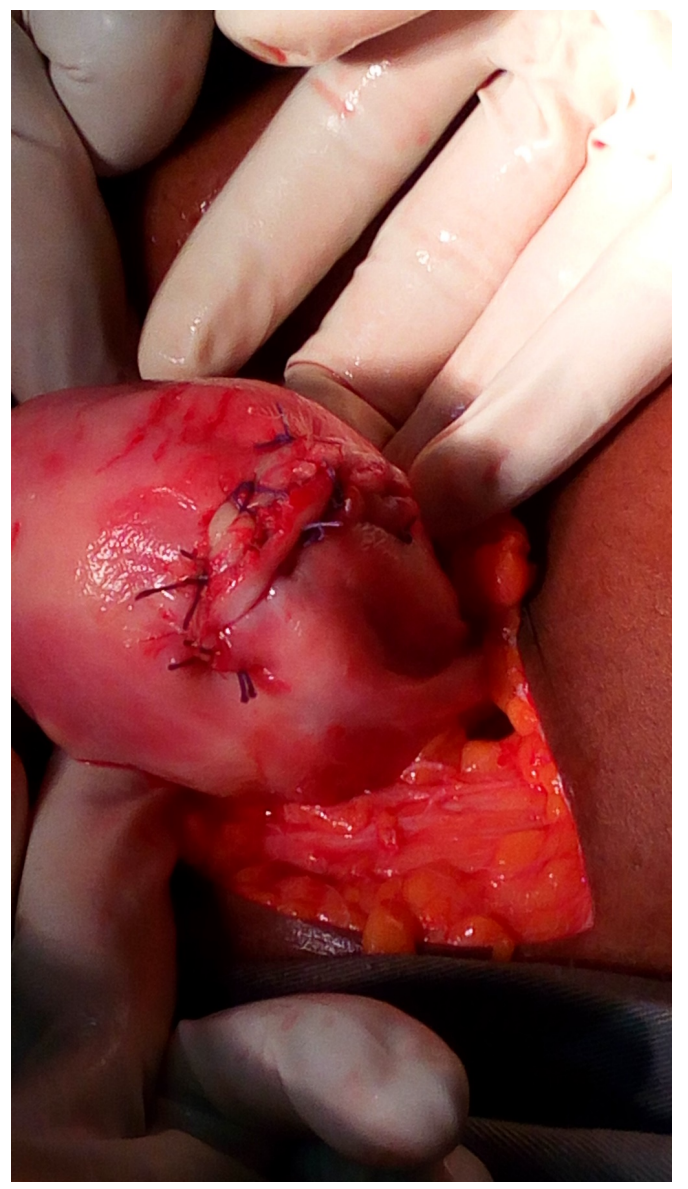

Figure 1. Appearance of uterus after conservative treatment.

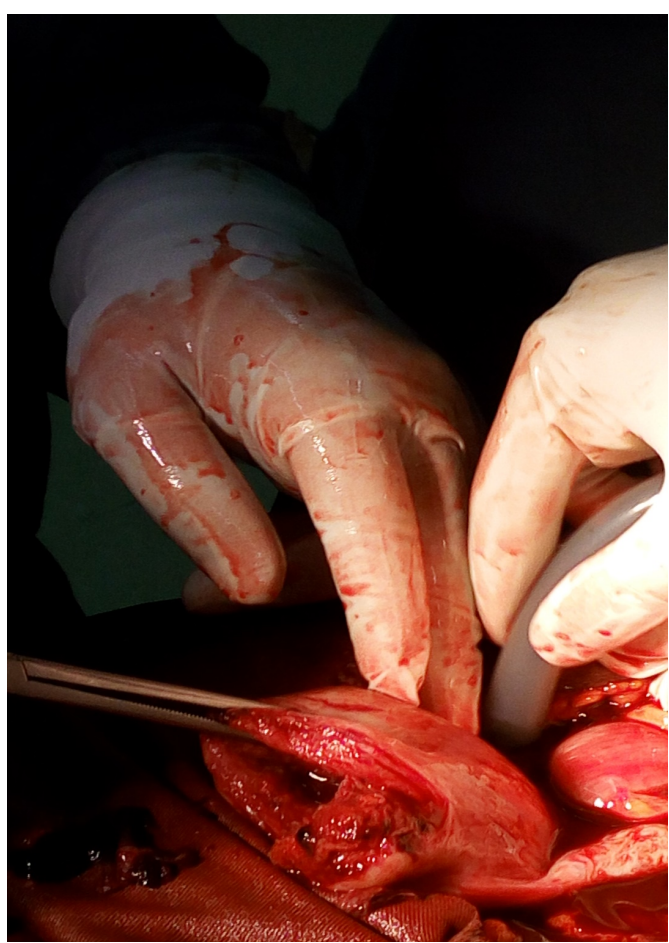

Figure 2. Exploration of uterine lesions during surgery (1). 


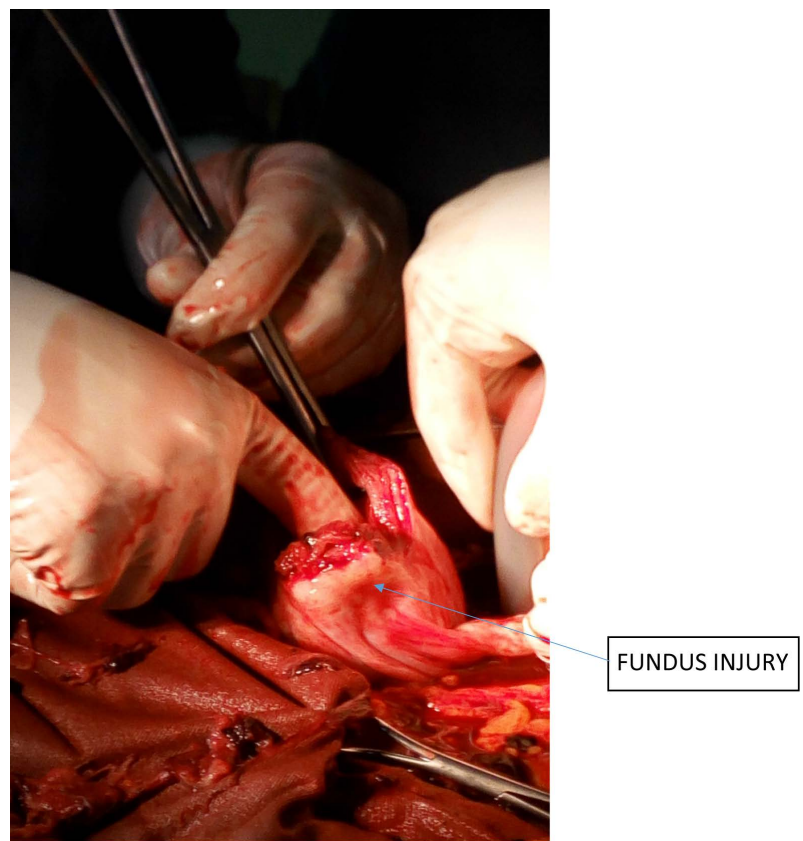

Figure 3. Exploration of uterine lesions during surgery (2).

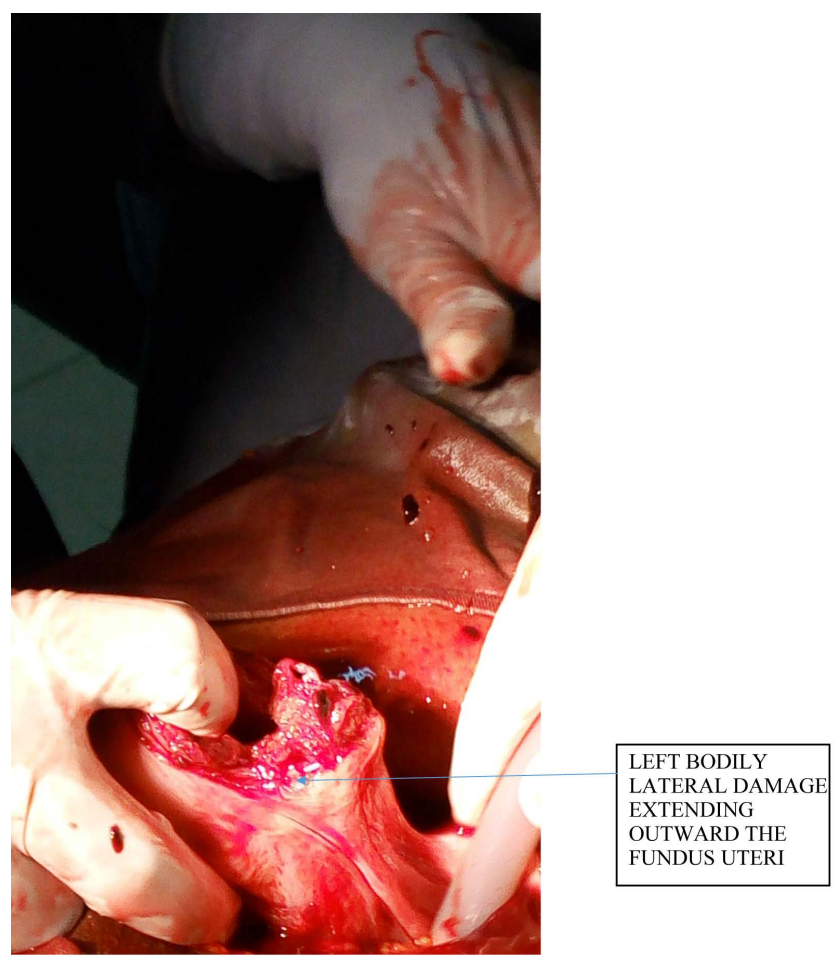

Figure 4. Exploration of uterine lesions during surgery (3).

There were no associated lesions of pelvic organs.

The exploration of the spleen and liver was normal.

A hysterorrhaphy was performed in 2 plans over sewing on the serosa (Figure 5). Haemostasis was satisfactory.

The peritoneum was closed after abdominal toilet with physiological saline. 


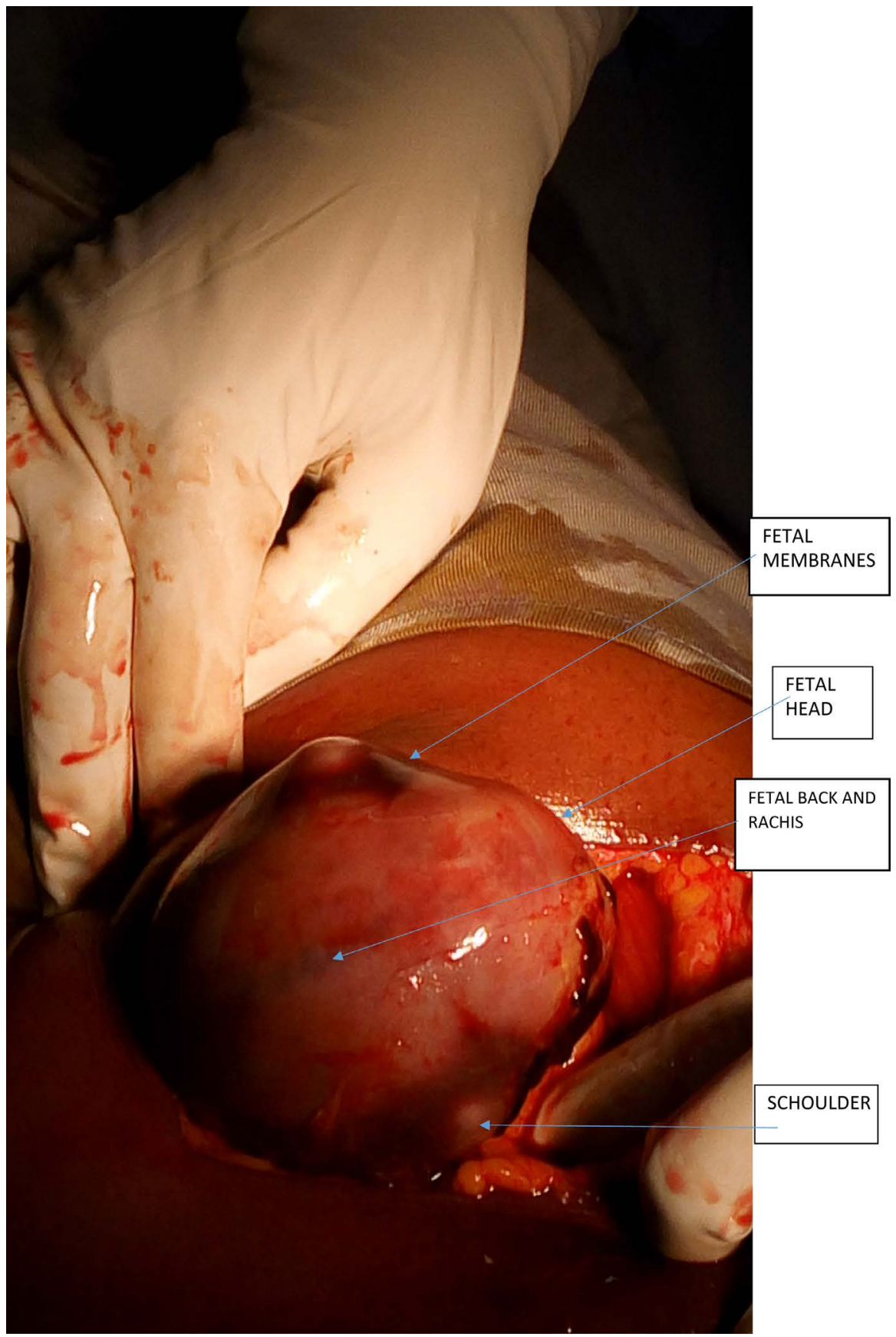

Figure 5. Fetus in its fetal annexes visualized during surgery before exploration.

During the procedure, the transfusion of $350 \mathrm{ml}$ of same blood group and $\mathrm{rh}$ compatible whole blood, as well as the day after the operation, was performed.

The initial demand for 4 pockets of blood could not be met due to the lack of availability of blood products.

There were smooth postoperatives recoveries, the resumption of bowel movement occurred at day 2 after surgery and allowed to institute a martial treatment at the rate of $200 \mathrm{mg}$ of ferrous iron per day.

The exit from hospital was allowed on day 5 after a verification of the hemog- 
lobin level which showed an increase to $8.2 \mathrm{~g} / \mathrm{dl}$. The continuation of iron therapy treatment out of hospital was recommended.

The dressings were made every two days until complete healing of the operative wound; no parietal complications have been noted.

Post-operative monitoring was normal: there were no complaints. The gynecological examination was strictly normal.

\section{Comments}

Uterine ruptures are very common in Africa and their incidence is estimated to be 1 in 70 to 151 deliveries.

The main etiologies reported are the following:

Cephalopelvic disproportions, dystocial presentations and misuse of oxytocic drugs [1].

Among these etiologies, trauma is rarely involved either in less than $1 \%$ of cases.

Although its precise incidence is not known, trauma is estimated to complicate 1 out of 12 pregnancies and lead to non-obstetric maternal death [2].

Uterine rupture is therefore a rare traumatic complication during pregnancy; traffic accidents are the most frequent causes with domestic violences also [3].

The interest of this observation is that in addition to its rare character, it makes it possible to find the three delays of the model of Thaddeus and Maine described in 1994 [4].

\subsection{First Delay}

The first delay refers to the decision to go to a health service that takes into account the inadequacy of antenatal consultations.

The patient had no medical documentation attesting to her pregnancy status, i.e. neither maternity records, nor ultrasound.

In our countries, more than half of the patients consult only in the 2nd trimester of pregnancy, as already mentioned by Koné et al. in 1999 [5], even fewer patients realize even one ultrasound during pregnancy, thus making it difficult to assess gestational age. However, the management of emergency care in cases of trauma depends on this gestational age [6].

\subsection{Second Delay}

In this observation, the emergency was acknowledged by the patient and the bus driver, thus avoiding the first delay.

The mode of transport intervenes in the prognosis of the mother; the management of a road accident victim must be well codified when it concerns a pregnant woman [6].

However, during the trip, the driver of the bus preferred to shorten the journey so as not to waste time on his work schedule. Indeed, he would have explained to the patient that the geographical location of the health center would 
constitute a considerable detour for him!

The car driver therefore "graciously" dropped the patient off 200 meters far from its destination!

\subsection{Third Delay}

The patient consulted a private health center with an obstetrician gynecologist.

In this establishment, deliveries are regularly performed. Why an evacuation then?

Indeed, it should be said that, in a very common way, private health centers evacuate patients toward Teaching hospitals there is a threat on patients' life in anticipation of a fatal outcome; this could harm the reputation of these facilities, thus contributing to the third delay.

At the Teaching hospital of Yopougon, the patient was admitted to the operating room at the time of her admission, a much better time than in most studies where the average time taken to deal with emergencies in Africa often exceeds one hour, because of unavailability of surgical blocks, surgical material or surgeons themselves.

Unfortunately, despite the extreme obstetric urgency of uterine rupture, and despite the anxiety caused to the obstetricians, delays in taking care of patients remain still take a long time [7].

These delays are responsible for a not insignificant proportion of maternal death [7], whereas in industrialized countries where these clinical settings are much less common, the lethality rates are much lower because of the higher quality of technology platform and short time frames delays in care [8].

\subsection{The Precarity of Health Care}

The uterine stroke would be linked with abdominal position during pregnancy. This would explain why most uterine ruptures caused by traffic accident occur mostly in the 3rd trimester.

Contrary to the observation of Dao et al. [1], our patient is primiparous and would appear to be at the beginning of the 2 nd trimester; indeed, the fetal weight evaluated after laparotomy, would lead to a pregnancy of 19 to 20 weeks, which corresponds to the statements of the patient who evaluates her gestational age at 4 - 5 months.

Without being in the large abdomen, the uterus at this term of pregnancy is above the pubis, far beyond the bone protection of the pelvis. It is also possible that the bones of the pelvis were the traumatic impact on which the uterus struck.

It is important to note the maintenance of hemodynamic balance in this patient who presented a hem peritoneum of $2000 \mathrm{cc}$.

It is common to see among African women an unusual tolerance for important haemoperitoneum sometimes exceeding $3000 \mathrm{ml}$. This is all the more surprising given the prevalence of chronic iron deficiency anemia in our countries, 
linked in general to endemic parasitoses.

The lack of blood and its derivatives is a real problem for our developing countries, and these haemoperitoneum are therefore never totally compensated. Martial treatment is systematically prescribed based on the experience of practitioners on the efficacy of one or the other of the products.

Parenteral martial treatments that allow a rapid rise in hemoglobin are certainly a good alternative to this unavailability of blood outside the emergency but this unavailability will remain for a long time one of the causes of the lethality of maternal hemorrhage [5].

In most cases, the authors describe a conservative treatment in nulliparous and/or young patients after rapid intensive care [9].

But in general, hysterorrhaphy is practiced when the extent of the lesions allow it, and especially in the African context where ablation of the uterus is considered as a major mutilation.

In most cases, there is fetal death and this fetal death is not necessarily correlated with the importance of trauma [10].

Concerning our patient, the fetus was dead; the trauma was violent, of course, but fetal death is probably related to placental detachment following uterine rupture as in most cases described in the literature;

The immediate clinical evolution is favorable according to all the above-mentioned authors, as well as at a distance from the accident, which demonstrates the relevance of the surgeons' choice to conservative treatment and also the surgical expertise of the practitioners in charge of these patients.

\section{Conclusions}

Traumatic uterine rupture is a rare complication during pregnancy, and is often related to a traffic accident.

The management of the injured pregnant woman must meet well-defined principles in order to improve the maternal and fetal prognosis. In most cases, the fetus dies during these uterine ruptures, and the maternal evolution depends on the extent of the lesions.

The possibility of associated lesions must not be lost of sight, as they can also threaten the prognosis of maternal survival.

The specificity of this management in the developing countries is that the 3 delays of the Thaddeus and Maine regimen are still found.

Informed consent was obtained from the patient to report her case.

\section{References}

[1] Dao, B., Ouattara, S., Some, D.A. and Sioho, N. (2009) Uterine Rupture by Road Accident: About a Case. Clinics in Mother and Child Health, 6, 1029-1031. (Article in French)

[2] Hill, C.C. and Pickinpaugh, J. (2008) Trauma and Surgical Emergencies in the Obstetric Patient. Surgical Clinics of North America, 88, 421-440.

https://doi.org/10.1016/j.suc.2007.12.006 
[3] Mendez-Figueroa, H., Dahlke, J.D., Vrees, R.A. and Rouse, D.J. (2013) Trauma in Pregnancy: An Updated Systematic Review. American Journal of Obstetrics \& Gynecology, 209, 1-8. https://doi.org/10.1016/j.ajog.2013.01.021

[4] Thaddeus, S. and Maine, D. (1994) Too Far to Walk: Maternal Mortality in Context. Social Science \& Medicine, 38, 1091-1101. https://doi.org/10.1016/0277-9536(94)90226-7

[5] Koné, M., Touré, A. and Apollinaire, H. (1999) Particularities of Pregnancy and Childbirth Monitoring in Africa in EMC, 5-043-A-60. EMC, Saint Paul. (Article in French)

[6] Jain, V., Chari, E.R., Maslovitz, E.S. and Farine, D. (2015) Guidelines for the Management of a Pregnant Trauma Patient. Journal of Obstetrics and Gynaecology Canada, 37, 553-571. https://doi.org/10.1016/S1701-2163(15)30232-2

[7] Abauleth, Y.R., Koffi, A.K., Cissé, M.L., Boni, S., Djanhan, Y. and Janky, E. (2006) Prognosis of Uterine Rupture during Labor: About 293 Cases Collected at the Bouaké University Hospital (Côte d'Ivoire). Journal of Medicine in the Tropics, 66, 472-476. (Article in French)

[8] Parant, O. (2012) Uterine Rupture: Prediction, Diagnosis and Management. Gynecol Obstet Biol Reprod, 41, 803-816. (Article in French) https://doi.org/10.1016/j.jgyn.2012.09.036

[9] Vaysse, C, Mignot, F., Benezech, J.P. and Parant, O. (2007) Traumatic Uterine Rupture: A Rare Complication of Motor Vehicle Accidents during Pregnancy. A Case Report. Journal de Gynecologie, Obstetrique et Biologie de la Reproduction, 36, 611-614. (Article in French) https://doi.org/10.1016/j.jgyn.2007.05.008

[10] Baerga-Varela, Y., Zietlow, S.P., Bannon, M.P., Harmsen, W.S. and Ilstrup, D.M. (2000) Trauma in Pregnancy. Mayo Clinic Proceedings, 75, 1243-1248. https://doi.org/10.4065/75.12.1243

\section{Submit or recommend next manuscript to SCIRP and we will provide best service for you:}

Accepting pre-submission inquiries through Email, Facebook, LinkedIn, Twitter, etc. A wide selection of journals (inclusive of 9 subjects, more than 200 journals)

Providing 24-hour high-quality service

User-friendly online submission system

Fair and swift peer-review system

Efficient typesetting and proofreading procedure

Display of the result of downloads and visits, as well as the number of cited articles

Maximum dissemination of your research work

Submit your manuscript at: http://papersubmission.scirp.org/

Or contact ojog@scirp.org 